\title{
Frequency, shape, and estimated volume of intracranial physiologic calcification in different age groups investigated by brain computed tomography scan: a retrospective study
}

\author{
Mehrdad Ghorbanlou, ${ }^{1,2}$, Fatemeh Moradi $^{3}$, Mehdi Mehdizadeh ${ }^{2,4}$ \\ ${ }^{1}$ Student Research Committee, Iran University of Medical Sciences, Tehran, ${ }^{2}$ Department of Anatomy, School of Medicine, Iran University of \\ Medical Sciences, Tehran, ${ }^{3}$ Department of Anatomy, School of Medicine, Zanjan University of Medical Sciences, Zanjan, ${ }^{4}$ Reproductive Sciences and \\ Technology Research Center, School of Medicine, Iran University of Medical Sciences, Tehran, Iran
}

\begin{abstract}
Intracranial calcification is referred to calcification of parenchyma and vascular structures in brain which can be physiologic or pathologic. This study was conducted with the purpose of investigating the frequency, location, pattern, dimensions and estimated volume of intracranial physiologic calcification (IPC) by computer tomography in different age groups. In this cross-sectional retrospective study, brain computed tomography scans of 216 patients were analyzed in 9 age groups each containing 24 patients from 2 to 89 years old. Data were analyzed by SPSS software using one way analysis of variance (ANOVA, post hoc Tukey), chi square, and linear regression tests ( $P \leq 0.05$ was considered significant). Rate of calcification in different areas were as follows: pineal gland (75.0\%), habenula (36.4\%), pineohabenula (15.0\%), right lateral ventricle choroid plexus (RCP) (67.7\%), left lateral ventricle choroid plexus (LCP) (62.7\%), falx cerebri (26.8\%), petroclinoid ligament (13.2\%), tentorium cerebelli (6.8\%), third ventricle choroid plexus $(0.9 \%)$, fourth ventricle choroid plexus (2.7\%), basal ganglia (0.9\%). A significant correlation exists between the presence of calcification in pineal, habenula, RCP, and LCP $(P \leq 0.001)$. Nodular shape of calcification was dominant $(47.9 \%)$. Estimated volume of pineal calcification showed increased levels in group 8 (70-79 years old) compared to group 2 (10-19 years old) $(P \leq 0.05)$. Since the accurate description of radiologic appearance of IPCs (location, shape, and size) accompanied with age and clinical manifestation is of great importance in diagnosis and distinguishing from pathologic calcification-for example in patients with melatonin dysregulation or schizophrenic patients—-this study was required.
\end{abstract}

Key words: Brain, Computed tomography, Calcification, Age

Received July 2, 2021; 1st Revised September 9, 2021; 2nd Revised September 23, 2021; Accepted September 28, 2021

Corresponding author:

Mehdi Mehdizadeh (10)

Department of Anatomy, School of Medicine, Iran University of Medical Sciences, Tehran 1449614535, Iran

E-mail: mehdizadeh.m@iums.ac.ir

Mehrdad Ghorbanlou (iD)

Department of Anatomy, School of Medicine, Iran University of Medical Sciences, Tehran 1449614535, Iran

E-mail: Mehrdad.ghorbanlou@gmail.com

\section{Introduction}

Intracranial calcification is referred to calcification of parenchyma and vascular structures in brain [1]. It can be manifested as a physiologic or pathologic process. Intracranial physiologic calcification (IPC) is a common finding in brain computed tomography [2] scans as this means of medical imaging can detect calcification relatively easily. 
Most frequent areas of brain prone to IPC are: pineal gland (pyramid-shaped gland located at the back of brain stem just above the superior colliculi) [3], habenula (an epithalamic structure functioning as an important connecting area) [4], choroid plexuses (vascular plexuses covered by cuboidal epithelial cells located in ventricles) [2], dura mater extensions (falx cerebri, tentorium cerebelli (TC), petroclinoid ligament [PCL] and etc.) [5], basal ganglia (BG) (located deep to neocortex involved in motor functions) [6].

Although pathologic calcification is rare, they can be interpreted as manifestations of certain diseases. These are: hereditary/developmental diseases (Sturge-Weber syndrome, cocaine syndrome, and etc.) [1,7], maternal/acquired diseases (cytomegalovirus, neonatal herpes, and etc.) [1,8], vascular (atherosclerosis) [1, 9], neoplastic (astrocytoma, medulloblastoma, and etc.) $[1,10]$, metabolic/endocrine (hypo-/ hyper parathyroid, hypothyroid disorder, and etc.) $[1,8]$, inflammatory (lupus erythematous, sarcoidosis, and etc.) [1], toxic (lead and carbon monoxide toxicity) $[1,11]$.

Various studies have reported the frequency and location of IPC [12-16]. In this study we analyzed IPC in different age groups of normal patients, and reported the frequency, age and sex dependency, pattern and shape, dimensions and estimated volume of IPC mainly in four common areas (pineal, habenula, and choroid plexuses of right and left lateral ventricles) prone to IPC. Since knowing the exact location, pattern and approximate volume of these calcifications is of importance to distinguish between physiologic and pathologic calcifications, this study was conducted.

\section{Materials and Methods}

\section{Patients and computed tomography}

This cross-sectional retrospective study was conducted after institutional review board approval (IR.IUMS. REC.1399.1288). Brain computed tomography (CT) scans of 216 patients were analyzed retrospectively for one year (2018 to 2019) in medical imaging center of Dr. Shariati Hospital, Mahdasht, Alborz, Iran. The patients were divided into 9 groups each containing 24 patients: group 1 (1-9 years old), group 2 (10-19 years old), group 3 (20-29 years old), group 4 (30-39 years old), group 5 (40-49 years old), group 6 (50-59 years old), group 7 (60-69 years old), group 8 (70-79 years old), group 9 ( $80-89$ years old).

Computer tomography imaging device was Hitachi-Supria 16/32 (Hitachi Medical Systems Europe [Holding] AG,
Zug, Switzerland) with $51 \mathrm{~kW}$ power, $75-\mathrm{cm}$ gantry bore, $180-\mathrm{cm}$ scan range, 5 mega hit unit (MHU) X-ray tube, and 0.675-mm minimum slice thickness.

Before entering the study, medical history of patients were reviewed and patients with diabetes, previous stroke, and renal failure were excluded from the study. While acquiring the CT scans, patients had to stay still in order to avoid motion artifacts. CT scans from the foramen magnum to vertex with 5-mm thickness and 5-mm interval were acquired, then the images were reconstructed with thickness and interval of $1.25-\mathrm{mm}$ in order to analyze the calcification more accurately.

\section{Areas and patterns of calcification}

Common areas investigated for IPC were pineal gland, habenula, choroid plexuses of lateral ventricles, third and fourth ventricles, BG, falx cerebri, TC, and PCL. Besides frequency distribution of calcification in different age groups, pattern and shape of calcifications were investigated including nodular (calcifications like nodules with welldefined margins), punctate (round and small calcifications with dimensions less than $1 \mathrm{~mm}$ ), diffuse punctate (multiple punctate calcifications), coarse conglomerated (calcifications with ill-defined margins), linear (elongated calcification), curvilinear (elongated curved calcifications), compound (calcifications which have different shapes at different sections), and circular peripheral (circular calcification around the periphery).

\section{Estimating volume of calcification}

$$
\text { Estimated volume }=\frac{\mathrm{A} \times \mathrm{B} \times \mathrm{C}}{2}
$$

Estimated volume of calcification can be measured by this formula (Fig. 1) [17-19]:

A: maximum anteroposterior length (APL) (mm) of calcification.

B: maximum mediolateral length (MLL) (mm) of calcification $90^{\circ}$ to $\mathrm{A}$ at the same slice.

C: maximum height of the calcification measured by the number of slices with visible calcification multiplied by the thickness $(1.25 \mathrm{~mm})$ of the CT-scan or a coronal plane was used.

Note that in order to measure the estimated volume of calcification, the slice with the biggest cross section is considered as the reference slice, then other slices are compared to 
the reference slice. Therefore, if one slice contains more than $75 \%$ of the calcification of the reference slice, it is considered 1 slice, if it contains $25 \%$ to $75 \%$ of the calcification of the reference slice, it is considered 0.5 slice, and if it contains less than $25 \%$ of the reference slice, it is considered 0 slice (Fig. 1).

\section{Statistical analysis}

Normal distribution of data was analyzed by Kolmogorov-Smirnov test. Normally distributed data of calci- fication dimensions and estimated volume were analyzed by analysis of variance (ANOVA) and post-hoc Tukey test. In order to investigate the correlation between two nominal qualitative variables (e.g., sex and presence of calcification), chi-squared test was performed, and for analyzing correlation between quantitative variables (e.g. estimated volume of calcification), linear regression was performed. Analyses were carried out by SPSS software, version 16 (SPSS Inc., Chicago, IL, USA). Data were presented as mean \pm standard

A Section 8

Section 6

Section 5

Section 4

Section 3

Section 2

Section 1

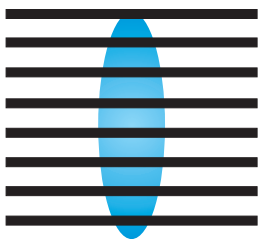

B

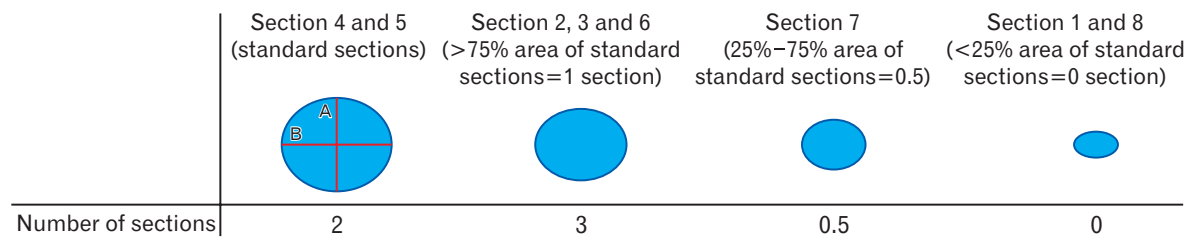

C A (maximum anteromedial diameter): $5 \mathrm{~mm}$

$B$ (maximum mediolateral diameter): $6 \mathrm{~mm}$

$C$ (maximum height: number of slices $\times$ thickness of

each section): $5.5 \times 1.25=6.87 \mathrm{~mm}$

Estimated volume $=\frac{A \times B \times C}{2}=\frac{5 \times 6 \times 6.87}{2}=103.05 \mathrm{~mm}^{3}$
Fig. 1. (A) A sample of how to calculate the estimated volume of calcification. A given calcification which can be detected in 8 slices in a computed tomography scan. (B) How to calculate the number of slices of calcification. (C) How to calculate estimated calcification volume according to $\mathrm{A} \times \mathrm{B} \times \mathrm{C} / 2$ formula (for example $A=5 \mathrm{~mm}, B=6 \mathrm{~mm}$, $\mathrm{C}[$ thickness $=1.25 \mathrm{~mm}$, number of slices $=5.5] 1.25 \times 5.5=6.87 \mathrm{~mm}$ estimated volume: $103.05 \mathrm{~mm}^{3}$ ).

Table 1. Demographic and calcification rate data

\begin{tabular}{|c|c|c|c|c|c|c|c|}
\hline \multirow{3}{*}{ Group (age, yr) } & \multirow{3}{*}{ Mean age (yr) } & \multicolumn{2}{|c|}{ Sex } & \multicolumn{4}{|c|}{ Calcification } \\
\hline & & \multirow{2}{*}{ Male } & \multirow{2}{*}{ Female } & \multicolumn{2}{|c|}{ Yes } & \multicolumn{2}{|c|}{ No } \\
\hline & & & & Male & Female & Male & Female \\
\hline \multirow[t]{2}{*}{$1(1-9)$} & $6.20 \pm 2.87$ & $12(50.0)$ & $12(50.0)$ & \multicolumn{2}{|c|}{$6(25.0)$} & \multicolumn{2}{|c|}{$18(75.0)$} \\
\hline & & & & 3 & 3 & 9 & 9 \\
\hline \multirow[t]{2}{*}{$2(10-19)$} & $15.54 \pm 2.97$ & $19(79.2)$ & $5(20.8)$ & \multicolumn{2}{|c|}{$21(87.5)$} & \multicolumn{2}{|c|}{$3(12.5)$} \\
\hline & & & & 17 & 4 & 2 & 1 \\
\hline \multirow[t]{2}{*}{$3(20-29)$} & $24.54 \pm 3.02$ & $15(62.5)$ & $9(37.5)$ & \multicolumn{2}{|c|}{$23(95.8)$} & \multicolumn{2}{|c|}{$1(4.2)$} \\
\hline & & & & 15 & 8 & 0 & 1 \\
\hline \multirow[t]{2}{*}{$4(30-39)$} & $35.16 \pm 3.10$ & $14(58.3)$ & $10(41.7)$ & \multicolumn{2}{|c|}{$24(100)$} & \multicolumn{2}{|c|}{0} \\
\hline & & & & 14 & 10 & 0 & 0 \\
\hline \multirow[t]{2}{*}{$5(40-49)$} & $44.25 \pm 3.30$ & $15(62.5)$ & $9(37.5)$ & \multicolumn{2}{|c|}{$24(100)$} & \multicolumn{2}{|c|}{0} \\
\hline & & & & 15 & 9 & 0 & 0 \\
\hline \multirow[t]{2}{*}{$6(50-59)$} & $55.25 \pm 2.67$ & $16(66.7)$ & $8(33.3)$ & \multicolumn{2}{|c|}{$24(100)$} & \multicolumn{2}{|c|}{0} \\
\hline & & & & 16 & 8 & 0 & 0 \\
\hline \multirow[t]{2}{*}{$7(60-69)$} & $64.12 \pm 2.80$ & $10(41.7)$ & $14(58.3)$ & \multicolumn{2}{|c|}{$24(100)$} & \multicolumn{2}{|c|}{0} \\
\hline & & & & 14 & 10 & 0 & 0 \\
\hline \multirow[t]{2}{*}{$8(70-79)$} & $73.45 \pm 2.73$ & $10(41.7)$ & $14(58.3)$ & \multicolumn{2}{|c|}{$24(100)$} & \multicolumn{2}{|c|}{0} \\
\hline & & & & 14 & 10 & 0 & 0 \\
\hline \multirow[t]{2}{*}{$9(80-89)$} & $83.62 \pm 3.03$ & $10(41.7)$ & $14(58.3)$ & & & & \\
\hline & & & & 14 & 10 & 0 & 0 \\
\hline Total & - & $121(56.0)$ & $95(44.0)$ & & & & \\
\hline & & & & 110 & 84 & 11 & 11 \\
\hline & & & & & & & \\
\hline
\end{tabular}

Values are presented as mean \pm SD or number (\%). -, not available. 
A $\square \mathrm{P} \square \mathrm{H} \square \mathrm{PH} \square \mathrm{RCP} \square \mathrm{LCP} \square \mathrm{FC} \square \mathrm{PCL} \square \mathrm{TC} \square$ 3rd V $\square$ 4th V $\square \mathrm{BG}$
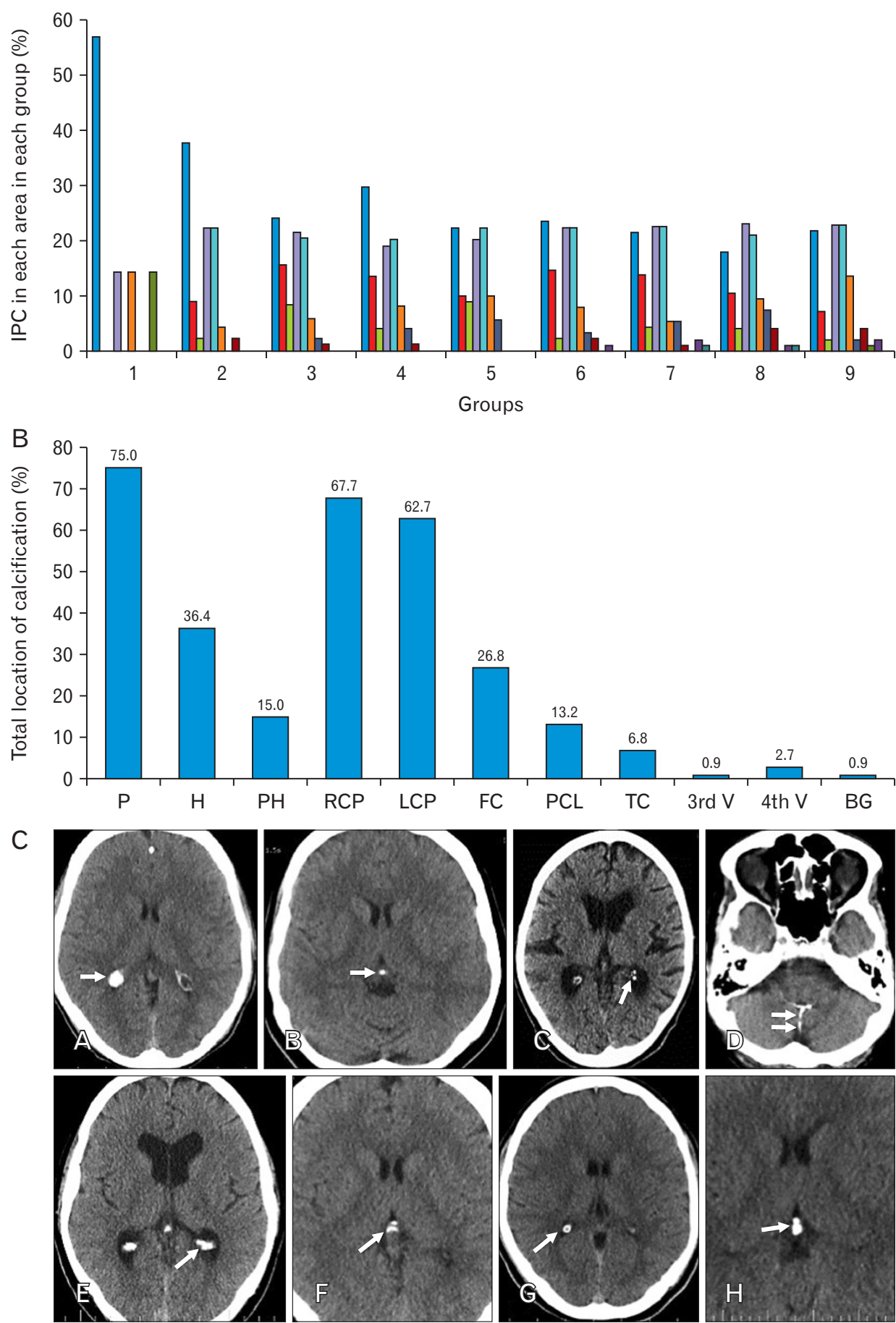

Fig. 2. (A) Percent of IPC in each area in each group. (B) Total location of IPC (percent). (C) Corresponding brain computed tomography images of various IPC patterns (A: nodular [dimensions $\geq 1 \mathrm{~mm}$ ]; B: punctate [dimensions $\leq 1 \mathrm{~mm}$ ]; C: diffuse punctate [multiple punctate calcifications]; D: linear; E: coarse conglomerated; F: curvilinear; G: circular peripheral; H: compound [pineohabenular calcification]). Arrow shows the calcification. (D) Percent of patterns of calcification in four common IPC areas. (E) Total pattern of calcification. IPC, intracranial physiologic calcification; P, pineal; H, habenula; PH, pineohabenula; RCP, right choroid plexus; LCP, left choroid plexus; FC, falx cerebri; PCL, petroclinoid ligament; TC, tentorium cerebelli; V, ventricle; BG, basal ganglia. 


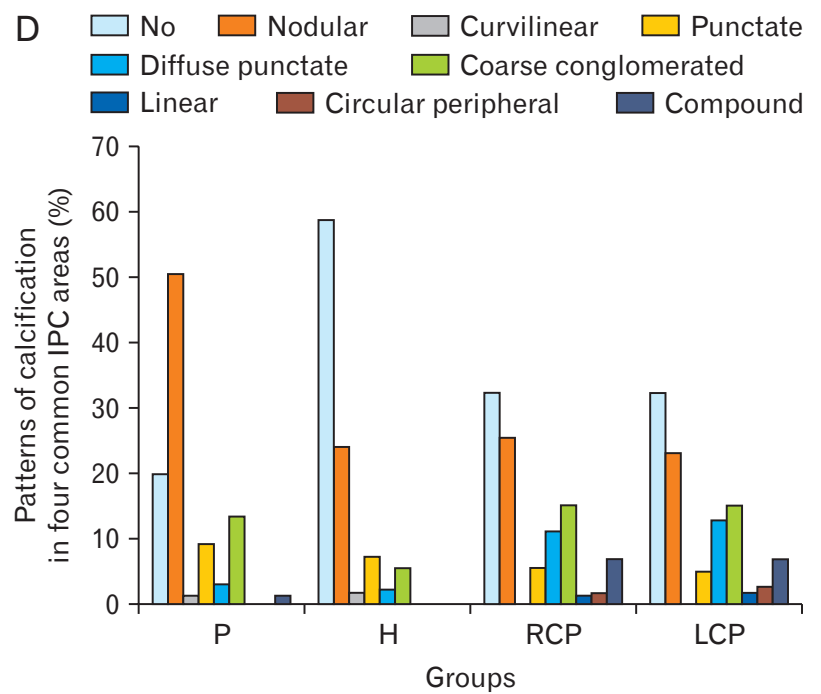

Fig. 2. Continued.

error of mean (SEM), and $P \leq 0.05$ was considered statistically significant.

\section{Results}

\section{Demographic data}

Among 216 patients entered the study, 56\% $(n=126)$ was male and $44 \%(n=95)$ was female. Distribution of age (mean \pm SEM) and sex in groups were as follows: group 1 $(6.20 \pm 2.87 ; 50.0 \%$ male $[\mathrm{M}], 50.0 \%$ female $[\mathrm{F}])$, group 2 $(15.54 \pm 2.97 ; 79.2 \% \mathrm{M}, 20.8 \% \mathrm{~F})$, group 3 (24.54 $23.02 ; 62.5 \%$ $\mathrm{M}, 37.5 \% \mathrm{~F})$, group $4(35.16 \pm 3.10 ; 58.3 \% \mathrm{M}, 41.7 \% \mathrm{~F})$, group 5 $(44.25 \pm 3.30 ; 62.5 \% \mathrm{M}, 37.5 \% \mathrm{~F})$, group $6(55.25 \pm 2.67 ; 66.7 \%$ $\mathrm{M}, 33.3 \% \mathrm{~F})$, group $7(64.12 \pm 2.80 ; 41.7 \% \mathrm{M}, 58.3 \% \mathrm{~F})$, group $8(73.45 \pm 2.73 ; 41.7 \% \mathrm{M}, 58.3 \% \mathrm{~F})$, group $9(83.62 \pm 3.03,41.7 \%$ M, 58.3\% F) (Table 1).

\section{Location and pattern of calcification}

Generally, IPC was detected, in at least one area, in $89.8 \%$ $(n=194)$ of the population leaving only $10.2 \%(n=22)$ noncalcified. Detailed rate of calcification in each area in each group is indicated in Fig. 2A. Location of IPC was as follows: pineal $(75.0 \%)$, habenula $(36.4 \%)$, pineohabenula $(15.0 \%)$, right lateral ventricle choroid plexus (RCP) (67.7\%), left lateral ventricle choroid plexus (LCP) (62.7\%), falx cerebri (26.8\%), PCL (13.2\%), TC (6.8\%), 3rd ventricle choroid plexus (0.9\%), 4th ventricle choroid plexus (2.7\%), and BG (0.9\%) (Fig. 2B).

Patterns of calcification were defined in four common IPC areas including pineal, habenula, RCP, and LCP in de-

\section{$E$} Total pattern of calcification (\%)
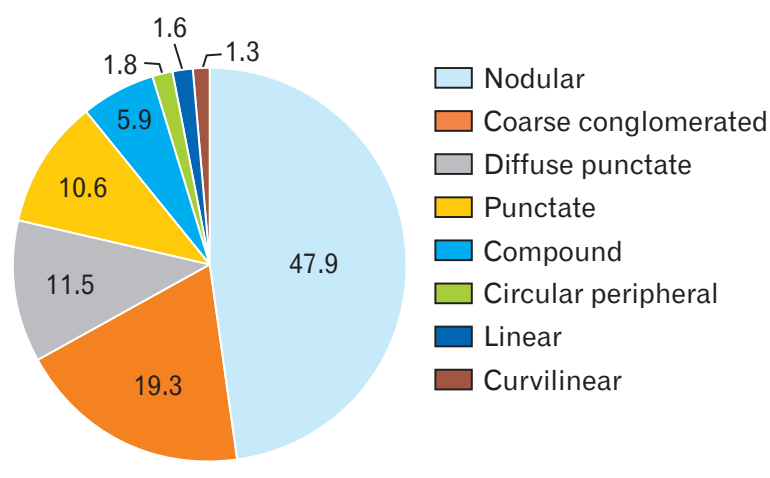

tail (Fig. 2D). In general, pattern of calcifications were $47.9 \%$ nodular, $19.3 \%$ coarse conglomerated, $11.5 \%$ diffuse punctate, $10.6 \%$ punctate, $5.9 \%$ compound, $1.8 \%$ circular peripheral, 1.6\% linear, and 1.3\% curvilinear (Fig. 2C, E).

\section{Dimensions and estimated volume of intracranial physiologic calcification}

\section{Pineal gland}

APL, MLL, approximate height (AH) (mean $[\mathrm{mm}] \pm \mathrm{SEM}$ ), and estimated volume (EV) (mean $\left[\mathrm{mm}^{3}\right] \pm$ SEM) of pineal calcification in groups were measured and no significant difference was detected between groups in APL; MLL in group 8 (4.56 \pm 0.42$)$ was significantly higher than MLL in group 2 $(2.78 \pm 0.25)(P \leq 0.05)$; differences between groups in $\mathrm{AH}$ were not significant; and EV in group $8(35.86 \pm 1.83)$ was significantly higher than EV in group $2(7.43 \pm 1.1)(P \leq 0.05)$ (Table 2, Fig. 3A).

\section{Habenula}

Significant increase in APL was detected in group 2 (3.5 \pm 0.66$)$ and $6(3.16 \pm 0.22)$ compared to group $9(2.01 \pm 0.24)$ $(P \leq 0.05)$; MLL in group $8(4.22 \pm 0.6)$ and $5(3.97 \pm 0.37)$ was significantly higher than MLL in group $9(2.05 \pm 0.14)$ $(P \leq 0.05)$; AH showed no significant difference between groups; and no significant difference was detected between groups in EV, as well (Table 2, Fig. 3B). 


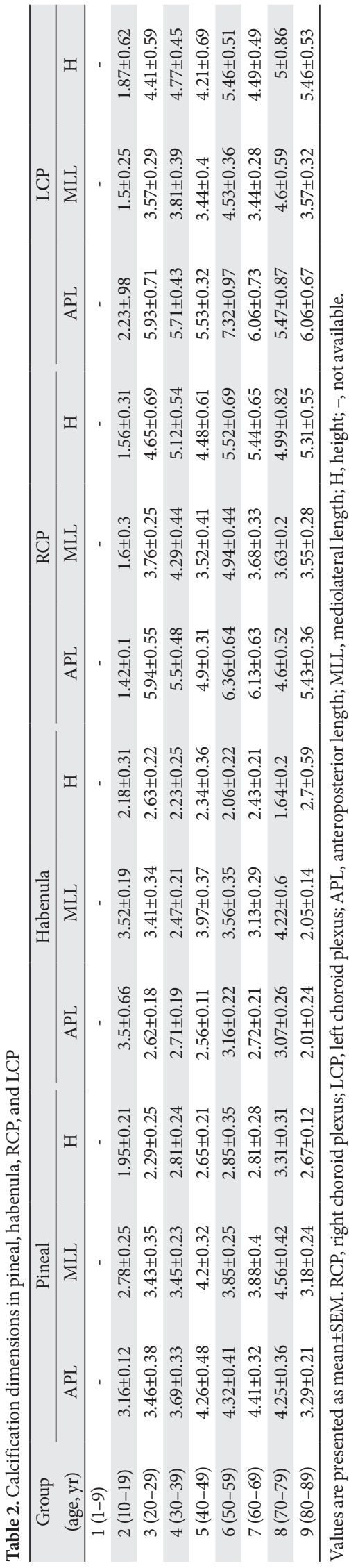

Right lateral ventricle choroid plexus

APL in groups $3(5.94 \pm 0.55), 4(5.5 \pm 0.48), 5(4.9 \pm 0.31)$, $6(6.36 \pm 0.64), 7(6.13 \pm 0.63), 9(5.43 \pm 0.36)$ was significantly higher than group $2(1.42 \pm 0.1)$. MLL in groups 4 $(4.29 \pm 0.44)$ and $6(4.94 \pm 0.44)$ was higher than group 2 $(1.6 \pm 0.3)(P \leq 0.05)$. AH was significantly higher in group 6 (5.52 \pm 0.69$)$, and group $7(5.44 \pm 0.65)$ compared to group 2 $(1.56 \pm 0.31)(P \leq 0.05)$. EV was significantly higher in group $6(84.88 \pm 10.87)$ compared to group $2(1.82 \pm 0.45)(P \leq 0.05)$ (Table 2, Fig. 3C).

\section{Left lateral ventricle choroid plexus}

No significant difference was detected between groups for APL. MLL was significantly higher in group $6(4.53 \pm 0.36)$, and $8(4.6 \pm 0.59)$ compared to group $2(1.5 \pm 0.25)$. AH was not significantly different between groups. EV in group $6(90.85 \pm 12.93)$ was significantly higher than group 2 (5.02 \pm 2.2 ) (Table 2, Fig. 3C).

\section{Correlation studies}

There is no correlation between pineal, habenula, falx cerebri, PCL, and TC calcification and sex, but RCP and LCP calcification is correlated to sex and their incidence is much higher in male than female $(P \leq 0.05)$. Chi square test showed a significant correlation between the presence of calcification in pineal gland, habenula, RCP and LCP $(P \leq 0.001)$.

Although in general, the incidence of calcification is increased by age, the presence and estimated volume of calcification were not significantly correlated with age.

There were no significant correlation between the estimated volume of calcification of pineal gland, habenula, RCP and LCP. Although the estimated volume of calcification in RCP and LCP were significantly correlated $(P \leq 0.001)$.

\section{Discussion}

This study showed that IPC occurred in $89.8 \%$ of patients and only $10.2 \%$ of patients did not have ICP - all the patients in groups 4-9 had at least one area of ICP, but there were some patients without calcification in groups 1-3. Although it is probably an age-related process [1], ICP presence did not show a significant difference in patients higher than 19 years old.

Pineal calcification mechanism is not clearly understood, but some hypotheses have been provided. One of them is the age-related calcification within the connective tissue of 
A

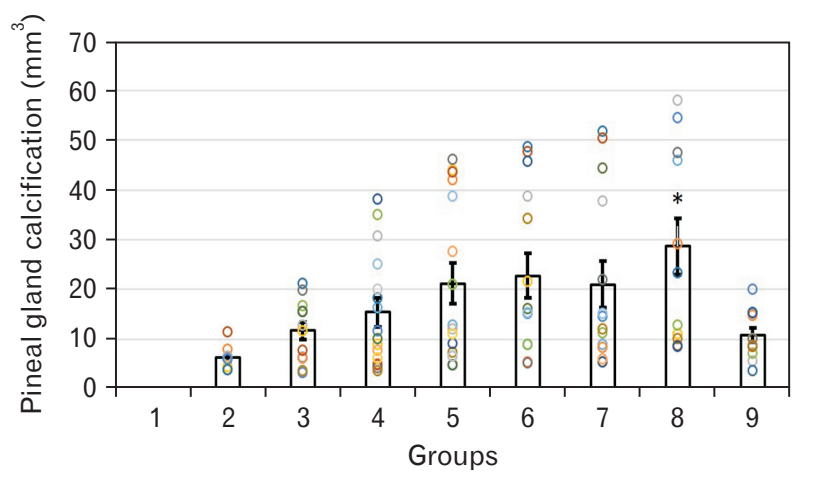

B

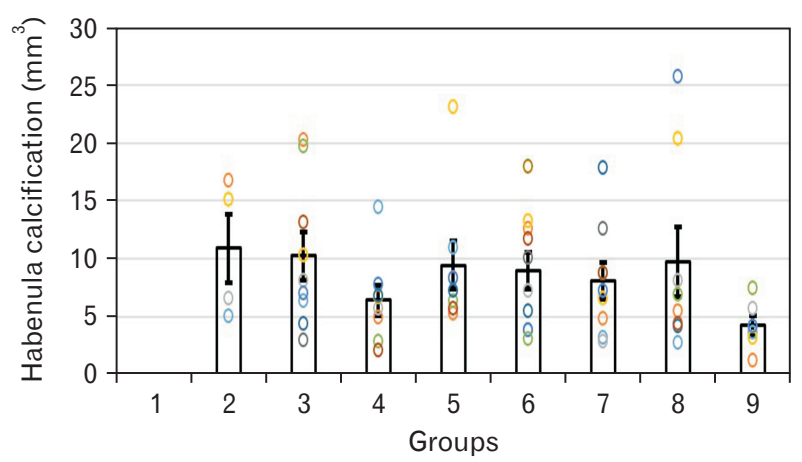

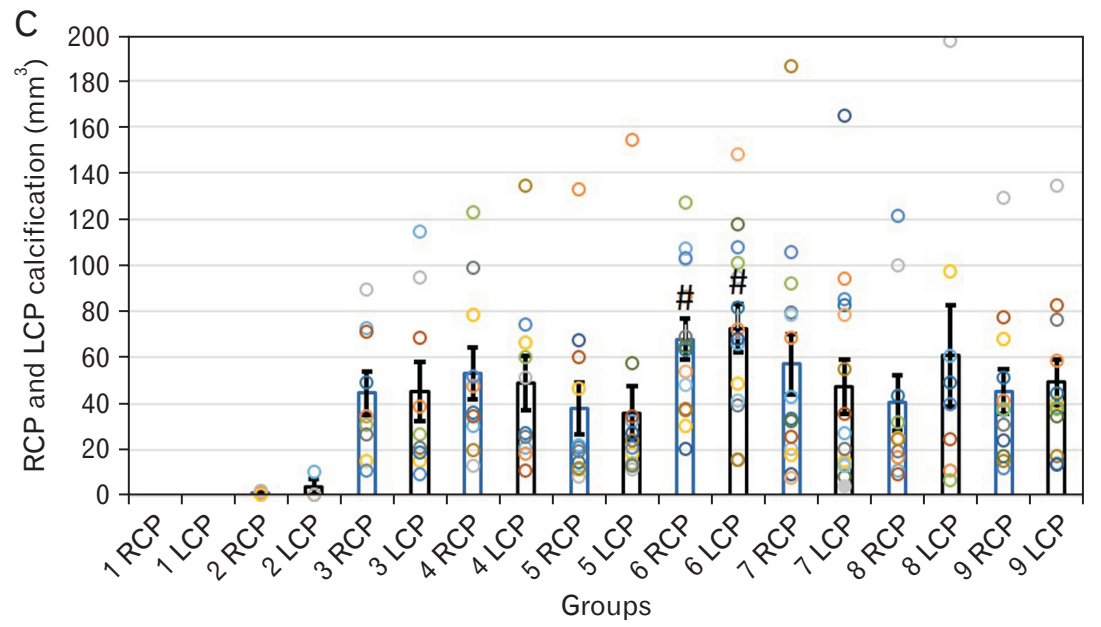

Fig. 3. (A) Estimated volume of pineal gland calcification. (B) Estimated volume of habenula calcification. (C) Estimated volume of RCP (blue boxes) and LCP calcification (black boxes). ${ }^{*} P \leq 0.05$ vs. group $2 ;{ }^{*} P \leq 0.05$ vs. group 2 . Data are reported as boxes with error bars indicating mean \pm SEM, and various circles in each column indicate individual data points. RCP, right choroid plexus; LCP, left choroid plexus.

the gland [20]. The other is that the high vascular supply to pineal gland makes it a vulnerable organ for calcification because of chronic vascular inflammation which causes the mesenchymal stem cells (MSCs) migration or proliferation due to increased levels of cytokines and the interaction between MSCs and inflammatory mediators activates them for osteogenic differentiation [21, 22]. Pineal calcification had been the focus of several studies [13,23], since melatonin as the most important substance secreted by pineal gland can be affected by the process of calcification. Pineal gland calcification and decreased levels of melatonin can be considered as stroke risk factors [23] and is associated with schizophrenic patients [24]. In this study, pineal calcification rate was $75 \%$ and it had a nodular shape in $63 \%$ of cases. Other studies showed similar frequency of pineal calcification which were as follows: 71\% [12], 71.6\% [16], 67\% [13], 67.7\% [25]. Dimension and estimated volume of pineal gland calcification showed an age-related relationship which were highest in group 8.

Habenula, RCP and LCP calcification frequency in this study were $36.4 \%, 67.7 \%$, and $62.7 \%$, respectively. Nodular shape of calcification was the most prominent pattern of calcification in these areas. Frequency of habenula calcification was reported in other studies as $20.1 \%$ [12] and $19.2 \%$ [16]. As habenula is closely related to limbic system, its calcification had shown higher levels in schizophrenic patients [24]. Choroid plexuses because of their vascular structure are prone to calcification, as well. Their calcification was also reported as $66.2 \%$ [12] and 70.2\% [16]. Dimensions and estimated volume of habenula did not show an age-related pattern since it was the highest in groups 2 and 3, although the differences were not significant among groups. RCP and LCP calcification dimensions and estimated volume showed an age-related pattern and was significantly increased in group 6 compared to group 2 .

Correlation studies in our investigation showed no signif- 
icant correlation between sex and pineal, habenula, falx cerebri, PCL and TC calcification. Although calcification of RCP and LCP showed significant male dominance. Other studies have reported a male dominance of IPCs $[12,14,16]$. There is a significant correlation between the presence of pineal calcification and habenula, RCP and LCP calcification $(P \leq 0.001)$ but there were no significant correlation between the size of pineal calcification and habenula, RCP and LCP calcification. Although it is reported that physiologic calcification is increased with age $[12,15]$, there was no significant correlation between age and presence and volume of calcification.

Presence of pineal and habenula calcification in children under 10 years old was previously reported [26], in our study calcification of pineal, RCP and LCP and falx cerebri in children under 10 was reported as $16.66 \%, 8.33 \%$, and $4.16 \%$ respectively. Patients more than 80 years old did not show higher physiologic calcifications $[15,25]$, in our study no increased calcification was evident in this age group, as well.

This study investigated the IPC in different age groups. Since the accurate description of radiologic appearance of IPCs (location, shape, and size) accompanied with age and clinical manifestation is of great importance in diagnosis and distinguishing from pathologic calcification, this study was required. In addition calcification of pineal as the secretor of melatonin, and habenula as an important connection in limbic system are of essential importance, thus current study provides major data on the frequency, location, shape, dimensions, and estimated volume of calcification in these region in normal patients.

\section{ORCID}

Mehrdad Ghorbanlou:

https://orcid.org/0000-0002-5436-0074

Fatemeh Moradi: https://orcid.org/0000-0002-9043-0439

Mehdi Mehdizadeh:

https://orcid.org/0000-0002-9268-7318

\section{Author Contributions}

Conceptualization: MG, FM. Data acquisition: MG, FM. Data analysis or interpretation: MG. Drafting of the manuscript: MG. Critical revision of the manuscript: MM. Approval of the final version of the manuscript: all authors.

\section{Conflicts of Interest}

No potential conflict of interest relevant to this article was reported.

\section{Acknowledgements}

This research was funded by student research committee of Iran University of medical sciences (99-3-15-18468). We also express our gratitude to Mr. Habib Rostami as the supervisor of medical imaging department of Shariati hospital, Mahdasht, Iran and Tajhiz Teb Arka Iranian company.

\section{References}

1. Saade C, Najem E, Asmar K, Salman R, El Achkar B, Naffaa L. Intracranial calcifications on CT: an updated review. J Radiol Case Rep 2019;13:1-18.

2. Spector R, Keep RF, Robert Snodgrass S, Smith QR, Johanson CE. A balanced view of choroid plexus structure and function: focus on adult humans. Exp Neurol 2015;267:78-86.

3. Møller M, Baeres FM. The anatomy and innervation of the mammalian pineal gland. Cell Tissue Res 2002;309:139-50.

4. Boulos LJ, Darcq E, Kieffer BL. Translating the habenula-from rodents to humans. Biol Psychiatry 2017;81:296-305.

5. Adeeb N, Mortazavi M, Tubbs RS, Cohen-Gadol A. The cranial dura mater: a review of its history, embryology, and anatomy. Childs Nerv Syst 2012;28:827-37.

6. Lanciego JL, Luquin N, Obeso JA. Functional neuroanatomy of the basal ganglia. Cold Spring Harb Perspect Med 2012;2:a009621.

7. Pilli VK, Behen ME, Hu J, Xuan Y, Janisse J, Chugani HT, Juhász C. Clinical and metabolic correlates of cerebral calcifications in Sturge-Weber syndrome. Dev Med Child Neurol 2017;59:952-8.

8. Dinizio A, Vincent J, Nickerson J. Intracranial calcifications in the pediatric age group: an imaging review. J Pediatr Neuroradiol 2015;4:49-59.

9. Kim JM, Park KY, Bae JH, Han SH, Jeong HB, Jeong D. Intracranial arterial calcificationes can reflect cerebral atherosclerosis burden. J Clin Neurol 2019;15:38-45.

10. Grech R, Grech S, Mizzi A. Intracranial calcifications. A pictorial review. Neuroradiol J 2012;25:427-51.

11. Kontzialis M, Huisman TAGM. Toxic-metabolic neurologic disorders in children: a neuroimaging review. J Neuroimaging 2018;28:587-95

12. Daghighi $\mathrm{MH}$, Rezaei V, Zarrintan S, Pourfathi H. Intracranial physiological calcifications in adults on computed tomography in Tabriz, Iran. Folia Morphol (Warsz) 2007;66:115-9.

13. Kitkhuandee A, Sawanyawisuth K, Johns NP, Kanpittaya J, Johns J. Pineal calcification is associated with symptomatic ce- 
rebral infarction. J Stroke Cerebrovasc Dis 2014;23:249-53.

14. Sedghizadeh PP, Nguyen M, Enciso R. Intracranial physiological calcifications evaluated with cone beam CT. Dentomaxillofac Radiol 2012;41:675-8.

15. Turgut AT, Karakaş HM, Ozsunar Y, Altın L, Ceken K, Alıcıoğlu B, Sönmez I, Alparslan A, Yürümez B, Celik T, Kazak E, Geyik PÖ, Koşar U. Age-related changes in the incidence of pineal gland calcification in Turkey: a prospective multicenter CT study. Pathophysiology 2008;15:41-8.

16. Yalcin A, Ceylan M, Bayraktutan OF, Sonkaya AR, Yuce I. Age and gender related prevalence of intracranial calcifications in CT imaging; data from 12,000 healthy subjects. J Chem Neuroanat 2016;78:20-4.

17. Kothari RU, Brott T, Broderick JP, Barsan WG, Sauerbeck LR, Zuccarello M, Khoury J. The ABCs of measuring intracerebral hemorrhage volumes. Stroke 1996;27:1304-5.

18. Webb AJ, Ullman NL, Morgan TC, Muschelli J, Kornbluth J, Awad IA, Mayo S, Rosenblum M, Ziai W, Zuccarrello M, Aldrich F, John S, Harnof S, Lopez G, Broaddus WC, Wijman C, Vespa P, Bullock R, Haines SJ, Cruz-Flores S, Tuhrim S, Hill MD, Narayan R, Hanley DF. Accuracy of the ABC/2 score for intracerebral hemorrhage: systematic review and analysis of MISTIE, CLEAR-IVH, and CLEAR III. Stroke 2015;46:2470-6.

19. Won SY, Zagorcic A, Dubinski D, Quick-Weller J, Herrmann E, Seifert V, Konczalla J. Excellent accuracy of ABC/2 volume formula compared to computer-assisted volumetric analysis of subdural hematomas. PLoS One 2018;13:e0199809.

20. Macpherson P, Matheson MS. Comparison of calcification of pineal, habenular commissure and choroid plexus on plain films and computed tomography. Neuroradiology 1979;18:6772.

21. Ciavarella C, Gallitto E, Ricci F, Buzzi M, Stella A, Pasquinelli G. The crosstalk between vascular MSCs and inflammatory mediators determines the pro-calcific remodelling of human atherosclerotic aneurysm. Stem Cell Res Ther 2017;8:99.

22. Tan DX, Xu B, Zhou X, Reiter RJ. Pineal calcification, melatonin production, aging, associated health consequences and rejuvenation of the pineal gland. Molecules 2018;23:301.

23. Kitkhuandee A, Sawanyawisuth K, Johns J, Kanpittaya J, Tuntapakul S, Johns NP. Pineal calcification is a novel risk factor for symptomatic intracerebral hemorrhage. Clin Neurol Neurosurg 2014;121:51-4.

24. Sandyk R. Pineal and habenula calcification in schizophrenia. Int J Neurosci 1992;67:19-30.

25. Kwak R, Takeuchi F, Yamamoto N, Nakamura T, Kadoya S. [Intracranial physiological calcification on computed tomography (Part 2): calcification in the choroid plexus of the lateral ventricles]. No To Shinkei 1988;40:707-11. Japanese.

26. Whitehead MT, Oh C, Raju A, Choudhri AF. Physiologic pineal region, choroid plexus, and dural calcifications in the first decade of life. AJNR Am J Neuroradiol 2015;36:575-80. 